This item was submitted to Loughborough's Research Repository by the author.

Items in Figshare are protected by copyright, with all rights reserved, unless otherwise indicated.

\title{
Exploring the influence of big data on city transport operations: a Markovian approach
}

PLEASE CITE THE PUBLISHED VERSION

http://dx.doi.org/10.1108/IJOPM-03-2015-0179

\section{PUBLISHER}

(c) Emerald Publishing

\section{VERSION}

AM (Accepted Manuscript)

\section{PUBLISHER STATEMENT}

This work is made available according to the conditions of the Creative Commons Attribution-NonCommercialNoDerivatives 4.0 International (CC BY-NC-ND 4.0) licence. Full details of this licence are available at: https://creativecommons.org/licenses/by-nc-nd/4.0/

\section{LICENCE}

CC BY-NC-ND 4.0

\section{REPOSITORY RECORD}

Mehmood, Rashid, Roy Meriton, Gary Graham, Patrick Hennelly, and Mukesh Kumar. 2019. "Exploring the Influence of Big Data on City Transport Operations: A Markovian Approach". figshare.

https://hdl.handle.net/2134/24964. 


\section{Exploring the Influence of Big Data on City Transport Operations: a Markovian Approach}

\section{Abstract \\ Introduction}

Big data has the potential to revolutionize the art of supply chain management. However in spite of its widely reported strategic impacts, there is a paucity of empirical research exploring its influence on operations and production management. In this work we extend the findings of our framework and modelling study to examine a potential scenario of how big data on transportation capacity may impact on future cities supply chain management. Fosso Wamba et al., (2015, p.235) define big data as: "a holistic approach to manage, process and analyze the 5Vs (volume, velocity, variety, veracity, and value) in order to create actionable insights for sustained value delivery, measuring performance and establishing competitive advantages." Meanwhile, accompanying the dramatic rise in the "velocity" and "volume" of city data, the growth of urbanization has been dramatic in the last decade. Indeed, according to Lierow, (2014), it is expected that 70 per cent of the world's population will live in cities by 2050 . This rate has increased the pressure for adjusting the actual infrastructures, and investing in new ones, in order to support the flow of goods and people, as well as to minimize the associated impact related to environmental degradation and quality of life (Caragliu et al., 2011).

To manage this issue, an increasing number of cities around the world are adopting the concept of "smart cities" (Allwinkle and Cruickshank, 2011). A smart city is: "a city seeking to address public issues via information and communication technology-based solutions on the basis of a multi-stakeholder, municipally based partnership” (Manville et al., 2014, p.24). Further it has been theorized that a "big data" logistics system could be constructed on the 
“social materiality" or "superstructure” of a smart city (Leonardi, 2013).

Big data logistics can be defined as the modelling and analysis of urban transport and distribution systems, through large datasets created by GPS, cell phone and transactional data of company operations (Blanco \& Fransoo, 2013). The demands and requirements of city logistics are changing on a daily basis through innovations in technologies with smart computing. Increasingly the real time tracking of vehicles could facilitate more accurate resource pooling and capacity sharing. The logistic firm therefore requires more technical and technological support to handle the five V's (Fosso-Wamba et al., 2015).

City authorities and communities are using ever-growing bodies of data to improve their understanding of citizen behaviour, service usage and also to build service transparency and accountability. With the growth of big data there is privacy surveillance and data misuse challenges (Moir et al., 2014). Cities also face challenges around quality, comprehensiveness, collection and the analysis of data from various sources. However, big data also needs to be robust, accessible, and interpretable if it is to provide cities and organizations with meaningful opportunities and solutions.

Future city operations managers need strategic tools to help them realize a vision of an efficient and effective urban transportation network. For instance, in the city of Santander (in northern Spain) there are 20,000 sensors connecting buildings, infrastructure, transport, networks and utilities, offering a physical space for experimentation and validation of IoT functions ${ }^{1}$.

\footnotetext{
1 The Internet of Things (IoT) is the network of physical objects or "things" embedded with electronics, software, sensors and connectivity to enable it to achieve greater value and service by exchanging data with the
} 
The aim of this paper is to make a contribution to operations theory by exploring how big data will transform smart city transport operations. Furthermore, any smart city transportation solution based on big data would inevitably impact on the supply chain components that are inextricably linked with road transportation. Therefore, we also aim to offer a commentary of what this transformation could potentially mean for the practice of future supply chain management. In order to meet this aim we present results from a Markov study using its numerical solutions. This work is theoretically positioned to complement and extend the seminal articles of Fosso-Wamba et al., (2015) and Setia and Patel (2013) who theoretically explore the impact of technological absorptive capacity on logistics performance.

The paper is structured as follows: in the literature review we define big data and also highlight the risks and challenges of its integration into city-operations management (OM). An initial organizing framework is then presented, together with an associated scenario. In the fourth section, the research method and details of the modelling procedure are outlined. This is followed by the results section in which the initial framework is advanced through the development of smart city logistics operations model. In the final section, we outline the theoretical contribution of the work, its practical impact and suggest some future research avenues.

\section{Big Data: limitations, risks and challenges}

With the advent of the smart city there is starting to emerge a body of literature exploring the motivations of city operations designers to adopt big data (Scott, 2014). For instance, there is work exploring how software solutions like SAS2 can be applied to improve the time performance of the public transportation sector (Biederman, 2013). A number of studies

manufacturer, operator and/or other connected devices. Each thing is uniquely identifiable through its embedded computing system but is able to interoperate within the existing Internet infrastructure. 
predict the future development and impact of big data logistics. With respect to its process adoption there is recent research demonstrating that $30 \%$ of the shippers and $27 \%$ of the third party logistics (3PL) providers, stated that they were planning on adopting a big data initiative to improve delivery capability (Burnson, 2013). There are several papers describing the advantages that big data can play in the process of information and data retrieval. Mehmood et al., (2015) note that the cost of healthcare, according to World Health Organization is mostly due to system and operational inefficiencies; and that big data analytics can minimize these inefficiencies and improve the clinical processes resulting in better, preventive, personalized healthcare. Most notably McCrea, (2013) explains which big data processes are important to the area of transport management. These include: cleansing, harmonizing, combining and standardizing data, as well as data visualization.

The volume and velocity of data capture is much greater in a smart city environment. For instance, Miller (2013) describes new ways of gathering big data by crowdsourcing. The use of Geographical Information System (GIS) as a source of big data is also examined by McKinsey Global Institute (James et al., 2011) who also indicates sensors, GPS and social media as new data sources. The smart city practitioner could use such data for smart routing, car monitoring and localized services. It also holds benefits for both the government (e.g. urban planning) and companies (e.g. localized advertising, optimized routing).

However, it must be noted that big data also brings much greater complexity to logistics planning because of the 5V's. Volume or the large amount of data that either consume huge storage or entail of large number of records data (Russom, 2011). Velocity which is the frequency or the speed of data generation and/or frequency of data delivery (ibid., p.2). Variety to highlight that it is generated from a large variety of sources and formats and it is 
contained in multidimensional data fields (including structured and unstructured data (ibid., p.3).

Drawing on these definitions, Fosso-Wamba et al. (2015), include another two V's, that is Value (or the 4th of the Vs) in order to stress the importance of extracting economic benefits from the available big data (p. 235). They also argue that a fifth dimension 'Veracity' should be added to prior definitions of big data in order to highlight the importance of quality data and the level of trust in various data sources data (ibid., p. 234).

There are significant challenges in implementing big data at the operational and process levels (ibid., p. 234). This is a view supported by Li et al., (2015) who note that gathering and analysing more data does not always correlate with improved operational performance: "not everything can be digitised; and we cannot assume that automation is always advantageous to OM; this is because our ability to handle large amount of data (in real time) and use it to make both rapid and effective operational interventions in the cityscape, is limited. For instance, does having more freight and passenger data solve traffic congestion?" (p. 10). Likewise, assuming that possessing more data provides necessarily better models of reality may be an over-simplistic assumption. For example, although big data is very effective when detecting correlations, it may fail when pinpointing which correlations are meaningful.

\section{Risks and challenges}

The major risks identified in the literature are summarized in Table 1. They can be further categorized with respect to whether they are: "preventable risks", "strategy risks" and “external risks" (Kaplan \& Mikes, 2012, p.21). 
Table 1 Big data risks and challenges

\begin{tabular}{|c|c|c|}
\hline Risks and Challenges & Big Data Projects & Key authors \\
\hline Interpretation error & Personalized drugs using real time data & (Bielinski et al., 2014) \\
\hline Data sharing & Retailing moving to a feedback economy & (Rigby, 2015) \\
\hline Data ownership & Centro De Operacoes Prefeitura Do Rio & (Kitchin, 2014) \\
\hline Compliance issues & City logistics on a cloud platform & (Xu et al., 2014) \\
\hline Talent management & The industrial internet & (Bruner, 2015) \\
\hline Privacy invasion & Crowdsourcing and the last mile pick-up & (Gue, 2014) \\
\hline Security breaches & Banks and credit risk checks & (Kural and Billens, 2015) \\
\hline Data analytical tools & City-healthcare (ambulance) & (Mehmood and Lu, 2011) \\
\hline Agility & Toyota (city) supplier network & (Manyika et al., 2011) \\
\hline Strategic re-alignment & Decentralized "Mini factories" & $\begin{array}{l}\text { (Mourtzis and Doukas, } \\
\text { 2013) }\end{array}$ \\
\hline Unstructured data & IBM/Motorola Retail presence & (Whitier, 2014) \\
\hline
\end{tabular}

Preventable risks are internal risks that should be actively controlled for and avoided where possible. For instance, this would include data sharing, ownership, data cleaning and meeting compliance standards Rigby, (2015); Kitchin, (2014)). Strategy risks are rational, calculated risks that a smart city practitioner might take in order to seek advantage or competitive gain. This would include: decentralization and re-orienting global to local production logistics through the establishment of mini-factories (e.g. the production of medical products and supplies for local hospitals (Mourtzis and Doukas, 2013).

External risks are largely beyond the practitioners' control. For example, in Table 1 this would refer to the volume of unstructured data (Whitier, 2014) or whether there is a sufficient enough pool of skilled data scientists to enable big data process capabilities to be achieved (Bruner, 2015) .

Big data is also paving the way for the integration of operational, information, business, quality and other dimensions of enterprise. See (Ji-fan Ren, 2016), for example, where the 
authors examine the quality dynamics in big data environment that are linked with enhancing business value and firm performance. Also see (Ahmad and Mehmood, 2016) and (Ahmad and Mehmood, 2015) where enterprise systems and their performance are discussed in relation to smart cities, sustainability and logistics. The potential of logistics prototyping to develop "user-driven" and "SME" approaches to future city design and urban supply chain decision-making is explored in (Graham et al., 2015).

\section{Smart city transport operations framework}

Future cities are expected to embrace new technologies and the planning of operational related activities. These include transportation and healthcare which will be more dynamic than has been the case. Big data will play an important role in providing innovative day to day and emergency services in the cities (Alazawi et al., 2014a). Urban planners will be able to react to the emerging changes in demand within a much shorter period of time.

Autonomous vehicles and autonomic computing systems appear, currently, to be the main approaches that could improve efficiency and reliability and hence the sustainability of city transport and operations systems (Schlingensiepen et al., 2014; Schlingensiepen et al., 2016). Using emerging technologies, such as IoT, it will be easier to measure and monitor the carbon footprint of transport related activities at a micro-level. A city rich in sensors will be able to assess the health of the whole city and provide the necessary logistics data to policy makers enabling them to make decisions at operational levels with a much shorter time span of implementation.

The framework presented in Figure 1 is based on a scenario of a future city transportation centre. In which the capacity and demand of the city can be analysed in real-time. In such a 
city the transportation centre is the sole authority to plan and manage demand. This scenario would only allow autonomous vehicles in the city.

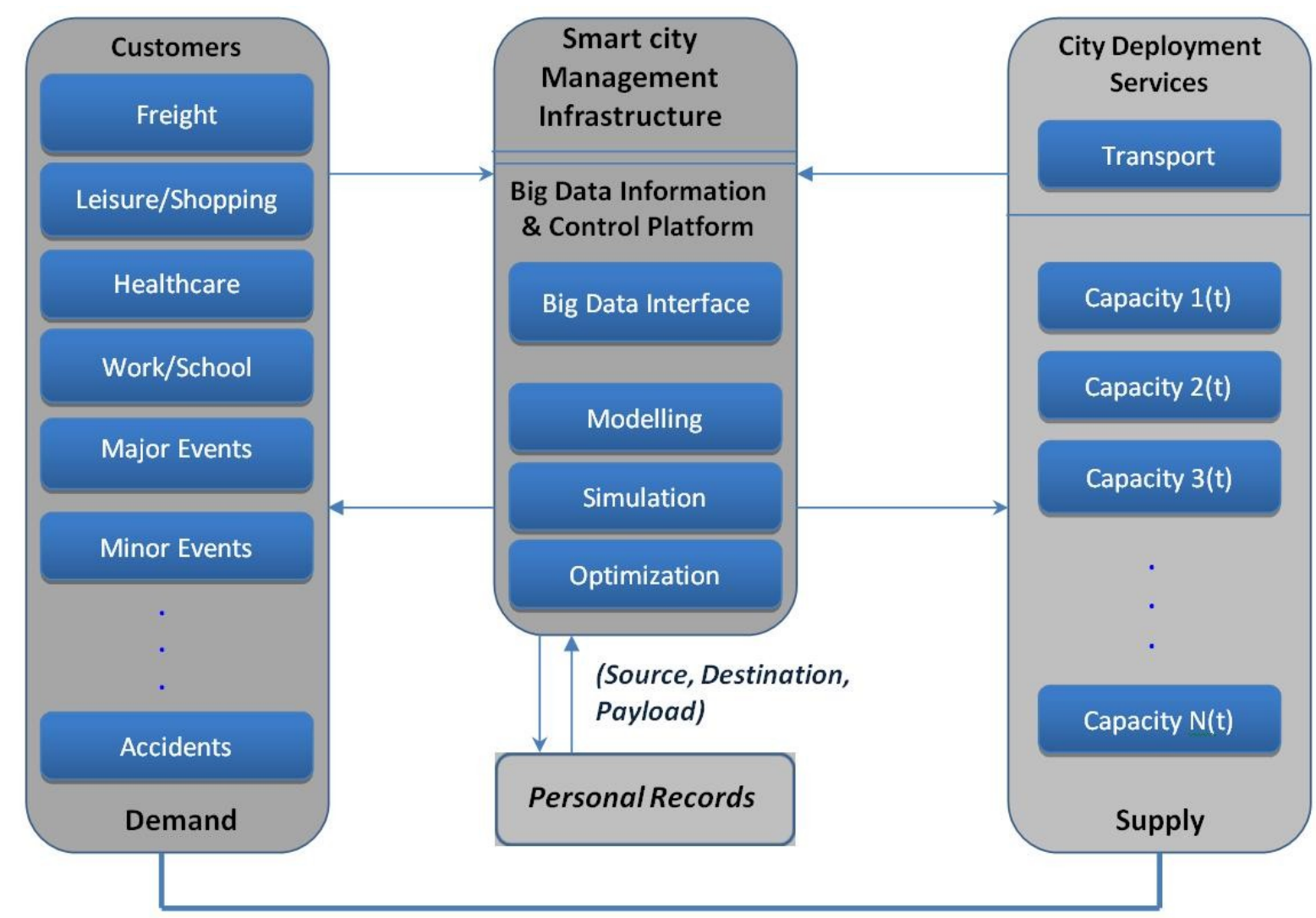

Figure 1 Big Data Operations Framework

The above was designed to provide a scenario for guiding the development of a Markov model. This transport centre monitors events in the city using sensor networks, big data and the Internet of Things (IoT). The centre takes real-time, short-term and long-term actions based on the operational data received. These actions may require immediate actions such as: making amendments in the traffic signalling schedules and dispatching additional autonomous vehicles to specific city zone(s) to meet the real-time and emerging demands. Consider a scenario where all the transport demand is planned and managed by the city transportation authority. It is able to receive various demand data for activities including: freight, healthcare, shopping and leisure, work and school. 
The data received can provide operational insight into short-run and long-run demand for activities affecting transport flows in the city. The data can also be live streamed data including the five Vs. For example, an intercity match in the city football stadium, which is being held in one month's time, would represent short-run demand data. Whilst the construction of a megamall in five years' time would be identified as long-run data, a major accident in the city centre a few minutes ago would be identified as a real-time shift in transportation demand.

\section{Research Method}

Markov chains, Markov decision processes (MDPs), queuing theory and discrete state models are widely used analysis, optimization and decision making tools. Markov chains allow systems of interest to be modelled as stochastic processes and the modelled systems can be analysed for their steady-state or time-dependent behaviour. Performance measures such as delay, blocking probability and utilization of a system can be calculated by computing the probability distributions of Markov chains. Markov decision processes allow systems to be modelled as optimisation problems.

Queuing theory based models allow systems of interest to be modelled as queues, or network of queues, with a certain arrival and service rate. Such formulations can be used to analytically calculate measures of interest including job loss probabilities and waiting times in the system. Arrival, queuing, service and departure are inherent in many science and technology problems and therefore many interesting systems can be formulated as queuing models. Markov chains, MDPs, and queuing theory are considered discrete state modelling tools because the modelled system is composed of discrete states making transitions from one state to another under certain constraints. Worthington, (1987); (1991) notes that queuing 
theory continues to be one of the most researched areas of city operations with its applications in coal mining, call centres, office processing, and retail (in addition to transport, telecommunications and healthcare).

Worthington, (1987) identifies five dimensions of queuing based modelling: single, multiand infinite server(s); exponential versus non-exponential, steady-state versus time-dependent analyses; single node, tandem queues; networks of queues; and extra features such as priority queues and server vacations. Worthington (1991) also identifies three distinct approaches in queuing based analysis: analytic formulations and formulae; analytic formulations and numeric solutions and models.

Batty, (2012); (2013) notes there is a critical need for understanding of big data explanatory models, based on explicit modelling assumptions, with predictive power. He strongly supports the use of concepts such as agent-based modelling (based on modelling each component of a system as a software agent), flocking (emulating or copying others' behaviour applied in artificial intelligence and software models) and graph theory. Markov chains, he suggests, provides an excellent starting point for big data analysis. Once a system has been modelled using this approach, its performance measures of interest can be derived by generating and solving a Markov Chain. The transient behaviour of a continuous time Markov chain (CTMC) is described by the Chapman-Kolmogrov differential equation:

$$
\frac{d \pi(t)}{d t}=\pi(t) Q
$$

where $Q \in \mathbb{R}^{n \times n}$ is the infinitesimal generator matrix, and $\pi(t)=\left[\pi_{1}(t), \pi_{2}(t), \ldots, \pi_{n}(t)\right]$ is the transient state probability row vector. The vector $\pi_{i}(t)$ denotes the probability of the 
CTMC being in state $i$ at time $t$, and $\pi_{0}$ is the initial probability distribution vector which equals $\pi(t)$ at $t=0$.

The steady state behaviour of a CTMC is given by:

$$
\pi Q=0, \quad \sum_{i=0}^{n-1} \pi_{i}=1
$$

where $\pi=\lim _{t \rightarrow \infty} \pi(t)$ is the steady state probability vector, which exists for an ergodic CTMC. The order of the infinitesimal generator matrix $Q$ equals the number of states in the CTMC. The off-diagonal elements of the matrix $Q$ satisfy $q_{i j} \in \mathbb{R}_{\geq 0}$, and the diagonal elements are given by $q_{i i}=-\sum_{j \neq i} q_{i j}$. The matrix $Q$ usually is very sparse; further details about the properties of these matrices can be found in (Stewart, 1991). The steady state equation given above can be reformulated as $Q^{T} \pi^{T}=0$, and the well-known methods for the solution of systems of linear equations of the form $A x=b$ can be used; see (Stewart, 1991) and (Kwiatkowska et al., 2011). The numerical solution methods for linear systems of the form $A x=b$ are broadly classified into direct methods and iterative methods. For large systems, direct methods become impractical due to the phenomenon of fill-in, caused by the generation of new entries during the factorisation phase. Iterative methods do not modify matrix A, rather, they involve the matrix only in the context of matrix-vector product (MVP). The term iterative method refers to a wide range of techniques that use successive approximations to obtain more accurate solutions to a linear system at each step. Since we deal with very large Markov chains, we mainly use iterative methods to solve the numerical models. 
A major hurdle in the applicability of these tools to complex and large problems is the 'curse of dimensionality problem'. This is because models for even trivial real life systems comprise of millions of states and hence require prohibitively large computational resources. This problem led to the development of several techniques designed to provide alternative strategies to solve large systems, such as concurrent, parallel and distributed computing techniques.

\section{Computational Methods to Solve Large Models}

We have previously developed computational strategies for the numerical solution of Markov chains, to exploit the developments in computational infrastructures and techniques which minimize the use of the resources, see (Mehmood, 2004a); (Mehmood \& Crowcroft, 2005); (Mehmood, 2004b); (Kwiatkowska et al., 2004); (Kwiatkowska et al., 2002); and (Kwiatkowska and Mehmood, 2002). The range of computational techniques which we have developed to resource minimize, include the following: 1) compact data structures which exploit model details to minimize the memory and computational requirements, 2) out-ofcore techniques which use concurrent programming (multithreading) and disk storage to efficiently store and retrieve large models, and 3) parallel computing techniques to use memory and computational power of multiple machines. For instance, the solution of CTMC models on single workstation as well as on parallel machines with over 1.2 billion states (equivalently, a linear system with 1.2 billion unknowns and equations) and 16 billion transitions.

Traditional solution methods will require over a 100GB of memory to store and solve such large systems, implying that these systems cannot be solved on a single contemporary 
workstation and will require fairly huge computational resources. This paper's framework coupled with this earlier work on the solution of large Markov models provides a promising approach for big data technologies and solutions to supplement previous applications of queuing theory (Freeman et al., (2000); Freeman and Burdon, (2013); Anderson et al., (2013)).

\section{Data and the capacity measure used in the Markov Model}

The Markov model used high level aggregate data or data aggregates that comprised a multitude or combination of freight, passenger ridership and service capacity data. This operational data was collected by the Massachusetts Bay Transport Authority (MBTA) and the Massachusetts Executive Office of Transportation in Boston ${ }^{1}$. It was made available to the authors in 2013 for Markov analysis after a period of 12 months from its collection. The use of aggregated data makes the assumption that the hypothesized relationship between the transport demand variables in question is homogenous across all individual cases (Garrett, 2003). Therefore, our findings on capacity-demand relationships are not valid for any individual variable (if less aggregated data were used). The aggregated capacity measure we used is the number of vehicles operating in the Kendall Square neighbourhood of Cambridge (per hour).

Correcting for 'aggregation bias' has received careful attention in the literature (Goodfriend, 1992). Therefore the findings are restricted to an aggregated operational perspective which is not generalizable to other city scenarios. It is only representative of one city borough's freight and passenger flows in one specific time period (May - August 2013) and it is not replicable to other time periods of that city area. Further, no externalities were factored into the model

\footnotetext{
${ }^{1}$ The Markov study formed part of a 3 month research investigation exploring future city logistics at MIT's Centre for Transportation and Logistics (http://www.nemode.ac.uk/?page_id=740)
} 
which might alter demand and supply patterns (e.g. season, climate, tourism, vacations, students (out of term)). A classic example of the approach presented here is the empirical work of Carroll et al., (1994) and Bram and Ludvigson (1998) who forecast national personal consumption expenditures through a highly aggregated measure of consumption.

Note that this section and the cited references herein, illustrate limitations of our approach, as well as example of research using this approach. In this research, we are concerned with aggregated traffic flows and centralised decision systems. Moreover, the problem illustrated is to determine the optimal allocation of autonomous vehicle to satisfy demand and capacity. As it is done by central authority and the use of aggregated data, we did not consider modelling transportation routes, traffic lights etc. However, it is possible to augment the model to a hierarchical Markov model with augmented state space representing routes and other constraints, and the solution principle will remain the same. Approaches of using Markov models for short term traffic forecasting are found in literature as well, see e.g. (Yu et al., 2003). The work of Büscher et al. (2009) is also relevant to our this work; they have explored cumulative, collective and collaborative aspects of mobility systems, and have illustrated challenges and opportunities in relation to practices of collaboration. A number of our earlier works have considered both macro-level and micro-level modelling and simulation of road traffic and transportation, see e.g. (Alazawi et al., 2014b, 2012, 2011, 2011; Ayres and Mehmood, 2009; Elmirghani et al., 2006; Mehmood, 2007; Mehmood and Nekovee, 2007).

\section{The Model}

A total of 18 scenarios were modelled based on various levels of transport demand and capacities in a future city. Subsequently, we calculated precise probabilities for all future 
states of each of the modelled scenarios. The analysis was designed along the lines of providing answers to questions such as: "What transportation capacity should I have in order to meet transportation demands of the city probability at $P=\alpha$ ? ” where $\alpha$ is the probability with any value between zero and one. The framework also allowed practitioners to determine the level of capacity sharing that is needed between various parts of the system.

Consider further that a future transportation centre plans and manages its long-run and shortrun transportation capacity periodically by analysing the quantitative changes in the demands, any related city activities, and historical trends. The short-run planning can be, for example, on a quarterly, monthly, or daily basis based on city dynamics. The long-run planning can be for a period of one year or more. The short-run and long-run planning can be carried out by building Markov models and solving these models for their steady-state numerical solution. Any real-time dynamics of the city are met by real-time planning algorithms, for example, by solving Markov models for their transient solutions. Optimization methods can also be employed, for example using Markov decision processes. We focus here on the steady-state solutions.

Let us denote the total transport demand of the city (in terms of the number of autonomous vehicles) by $\lambda_{T}$. This is per hour demand in terms of the arrival rates with exponentially distributed inter-arrival times. The total demand comprises $\lambda_{F}$ (demand for freight related activities), $\lambda_{H}$ (healthcare), $\lambda_{S L}$ (shopping \& Leisure) and $\lambda_{W}$ (work-related transportation demand). All these demands are per hour, in terms of the number of autonomous vehicles, with exponentially distributed inter-arrival times. Mathematically:

$$
\lambda_{F}+\lambda_{H}+\lambda_{S L}+\lambda_{W}=\lambda_{T}
$$


Now assume that the total transportation demand for the city for weekdays is 4800 autonomous vehicles per hour. Also, suppose that the transportation demand for the four named activities, freight, health, shopping \& leisure, and work are at $a=25 \%, b=15 \%$, $c=25 \%$, and $d=35 \%$ of the total transport demand, respectively. Formally, we can write as:

$$
\begin{gathered}
\lambda_{F}=1200\left(\lambda_{T} \times a\right), \lambda_{H}=720\left(\lambda_{T} \times b\right), \lambda_{S L}=1200\left(\lambda_{T} \times c\right), \\
\lambda_{W}=1680\left(\lambda_{T} \times d\right), \lambda_{T}=4800
\end{gathered}
$$

Note that our methodology to model the transportation demand of a future city does not depend on the number of transportation-related activities in the city (freight, work etc.) because you can add additional sub-demands for each new activity and include these in Equation (1) and (2). Similarly, it is also possible to build separate models for each change in the transportation demand, e.g. due to peak time and off-peak time demands, weekend demands. Similarly, the quantity of demand and capacity does not affect our methodology.

A smaller figure of 8000 vehicles per hour for transportation capacity is now used for explanatory purposes otherwise theoretically any quantity of transportation demand typical of a city can be modelled and numerically solved. For large demands, we can use the range of techniques that we have developed over the years to deal with large models; see Section "Computational Methods to Solve Large Models" on Page 12 for a discussion of the techniques for solving large Markov chains.

The operations centre considered various scenarios and possibilities for variations in the 
transportation demands in the city, included those discussed above (peak, off-peak, weekend, shift of higher work-related demand in the morning towards higher shopping and leisure related demands in the evenings). They decided to build transportation capacity in the city such that the typical workday demand is met by $60 \%$ of the total transportation capacity, that is:

$$
\mu_{T} \times 0.6=\lambda_{T}, \quad \mu_{T}=\frac{4800}{0.6}, \quad \mu_{T}=8000 .
$$

where $\mu_{T}$ is the total transportation capacity of the transportation system in the city. As for the demand, $\mu_{T}$ represents the transportation service rates with exponentially distributed service times. The service rate or the transportation capacity is modelled in this manner to take into account the random nature of shared capacity that would exist in a real city. So for example, one area of transport demand (e.g. school related transport) may have its peak time in the morning while another area of transport demand (e.g. leisure related transport) has its peak in the evening. So the capacity from one area of transport demand can be shared by another area of transport demand. Note that the term "capacity" in this paper is not strictly meant to be the term "capacity" as is taken in queuing theory discipline and the Kendall's notation; rather it is meant to be the transportation capacity in terms of the vehicles per hour that the transport operations centre is able to provide. The two connotations are interrelated here but could cause confusion if the differences are not understood.

Considering the variations in transport demand, the transportation centre modelled a number of scenarios ranging from $\lambda_{T}=1$ (a transport demand of one vehicle per hour) to $\lambda_{T}=8000$ (a transportation demand equal to the transportation capacity). We have modelled a total of 
18 such scenarios as CTMCs and have obtained the numerical solution for their steady state vectors.

The lowest demand case scenario $(\lambda=1)$ is selected such that the demand is relatively very small compared to the total capacity of the transport operation. This is to show that such a system will have high probability of being in the near idle states. The worst case scenarios represents a very high demand $(\lambda=7990$ and $\lambda=8000$ per hour) reaching very close and equal to the total capacity of the transport operations centre. Fifteen other scenarios $(\lambda=500$, $1000,1500, \ldots, 7500)$ in between these extremes were modelled to understand the dynamics of such a transportation planning and management centre.

Figure 5 (see Appendix on Page 43) gives the generic transition diagram of a CTMC applicable to all the 18 scenarios discussed earlier. The transition diagram depicts that the model has $N+1$ states. The initial state (numbered 0 ) represents the case where there are no demands or requests for vehicles in the system. The next state (numbered 1) represents the case where there is a demand for one vehicle in the system, and so on. The last state (numbered $N$ ) represents the case where the system contains the maximum number of jobs and is running at its full capacity $\left(\mu_{T}\right)$. The states numbered $J$ represent all the states between 4 and $N-1$.

The total number of states in the transition diagram (Figure 5, Appendix, Page 43) for all the 18 scenarios will be the same, i.e. 8001 . The departure rates will depend on the particular state the system is in, that is $\mu_{i}=i * \mu, \forall 0<i \leq 8000$ where $\mu=1$. The arrival rates however will be in accordance with the 18 scenarios, as mentioned earlier, $\lambda_{i}=\lambda=$ $1,500,1000, \ldots, 7500,7990,8000, \forall 0 \leq i<8000$. Essentially, this Markov model 
represents an $\mathrm{M} / \mathrm{M} / \mathrm{C}$ queuing system.

Table 2 (see Appendix, Page 43) gives the generator matrix (Q) of the CTMC model given in Figure 5. The diagonal elements are highlighted in the blue and bold font. Given the matrix Q, the steady state vector $(\pi)$ of the system (containing probability distribution of all the system states) can be calculated by solving the corresponding sparse system of linear equations as given by Equation (2). The system of linear equations can be solved using stationary methods like Jacobi and Gauss-Seidel (GS), and non-stationary methods such as Conjugate Gradient, Lanczos, etc. We have used both the Jacobi and Gauss-Seidel methods to solve large Markov chains with over a billion states (see Page 12). Figure 6 (Appendix, Page 44) gives the block Jacobi algorithm used to solve the CTMCs, taken from our earlier work (Mehmood \& Crowcroft, 2005); refer to the source for details of the algorithm.

\section{Results}

We have used two separate figures (Figure 2 and Figure 3) to make the results more comprehensible. First, the results are explained from a low demand scenario of 500 vehicles per hour. The horizontal axis is used for the states of the system. The vertical scale of probability ranges between 0 and 1 (where $1 \mathrm{E}-00$ is one and $1 \mathrm{E}-08$ indicates a small probability near zero). 


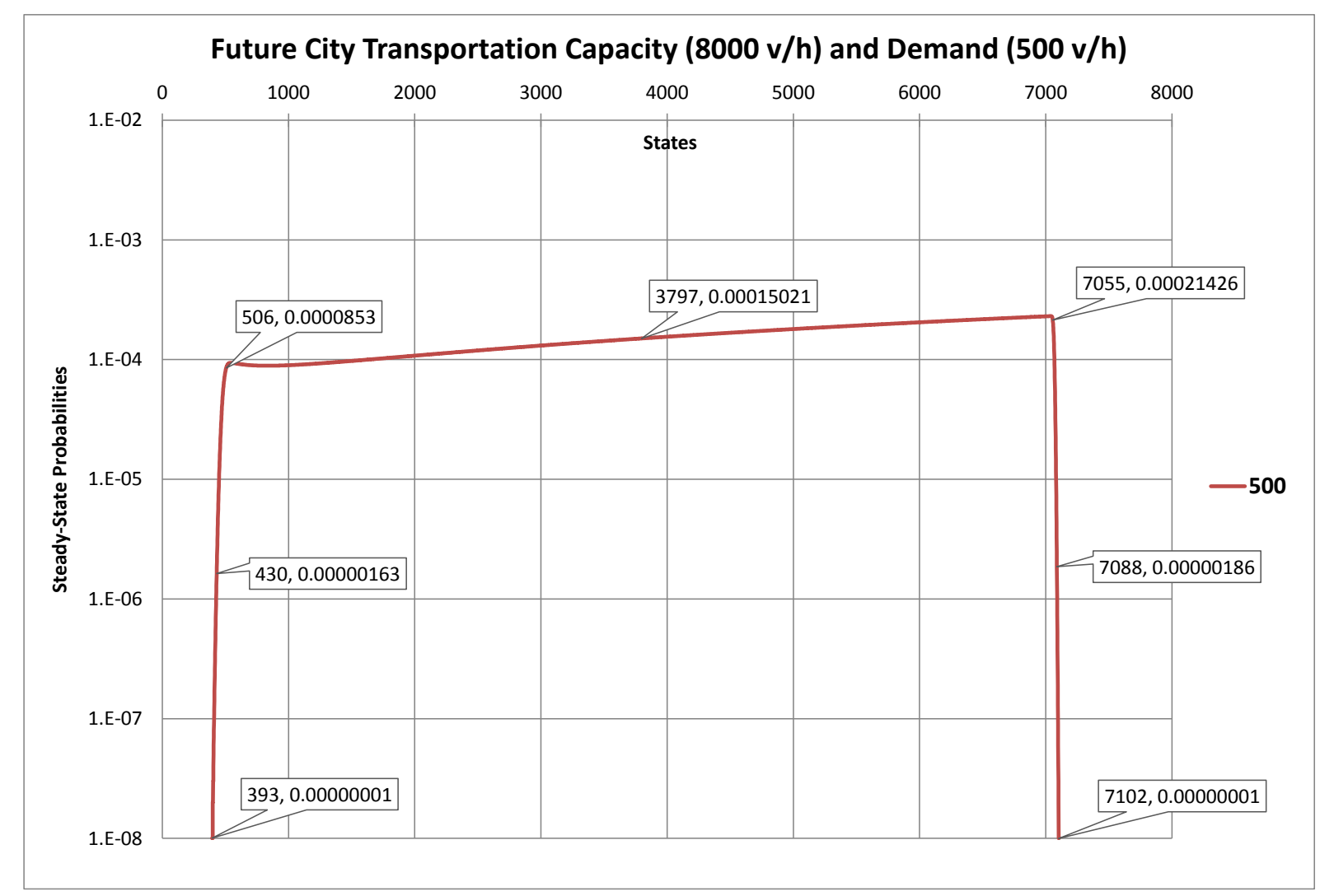

Figure 2 Transportation Capacity, demand, and steady state probabilities (500 vehicles per hour demand)

There are a total of 8001 states in the system: state 0 to state 8000 . State 0 means that the city transport system is idle and there is no vehicle demand in the system for autonomous vehicles. State 1 implies that there is a demand for one autonomous vehicle per hour, State 2 implies demand for two autonomous vehicles per hour, and so forth. The final state number is 8000, which implies that the transportation system is operating at its full capacity with 8000 autonomous vehicles being requested every hour by the city. As we have explained earlier, this modelled system is able to provide 8000 vehicles per hour capacity.

Both the arrivals and departures have exponentially distributed inter-arrival and service times. The vertical axis gives the stead y-state probabilities for the city transportation system. There 
are a total of 8001 states in the system: state 0 to state 8000 . The plot gives the probability of the system to be in each of the system states for the scenario with 500 vehicles per hour demand. We have labelled some of the plot values with the number of specific state and the associated probability.

The probability for such a system to be in state 393 is $1.0 \mathrm{E}-08$. The probability for the system to be in all the earlier states (states zero to 392) is zero. The absence of any dots or line represents a zero probability. Subsequently, the plot shows an increase in the nonzero probabilities, rising from the left of the plot to the values between 0.0001 (state 506) and 0.0002 (state 7055), approximately. Finally, to the right, the probabilities drop again to the value $1.0 \mathrm{E}-08$ (state 7102 ). The probabilities for states 7105 to 8000 , all are zero. We have used 1.E-08 as the vertical scale limit, and the logarithmic scale to make the graph comprehensible. The states with zero probability imply that the system will never reach to these states. For higher numbered states (7105 to 8000$)$, it demonstrates that the system is fairly stable, will comfortably deal with its load, and will not fail. 


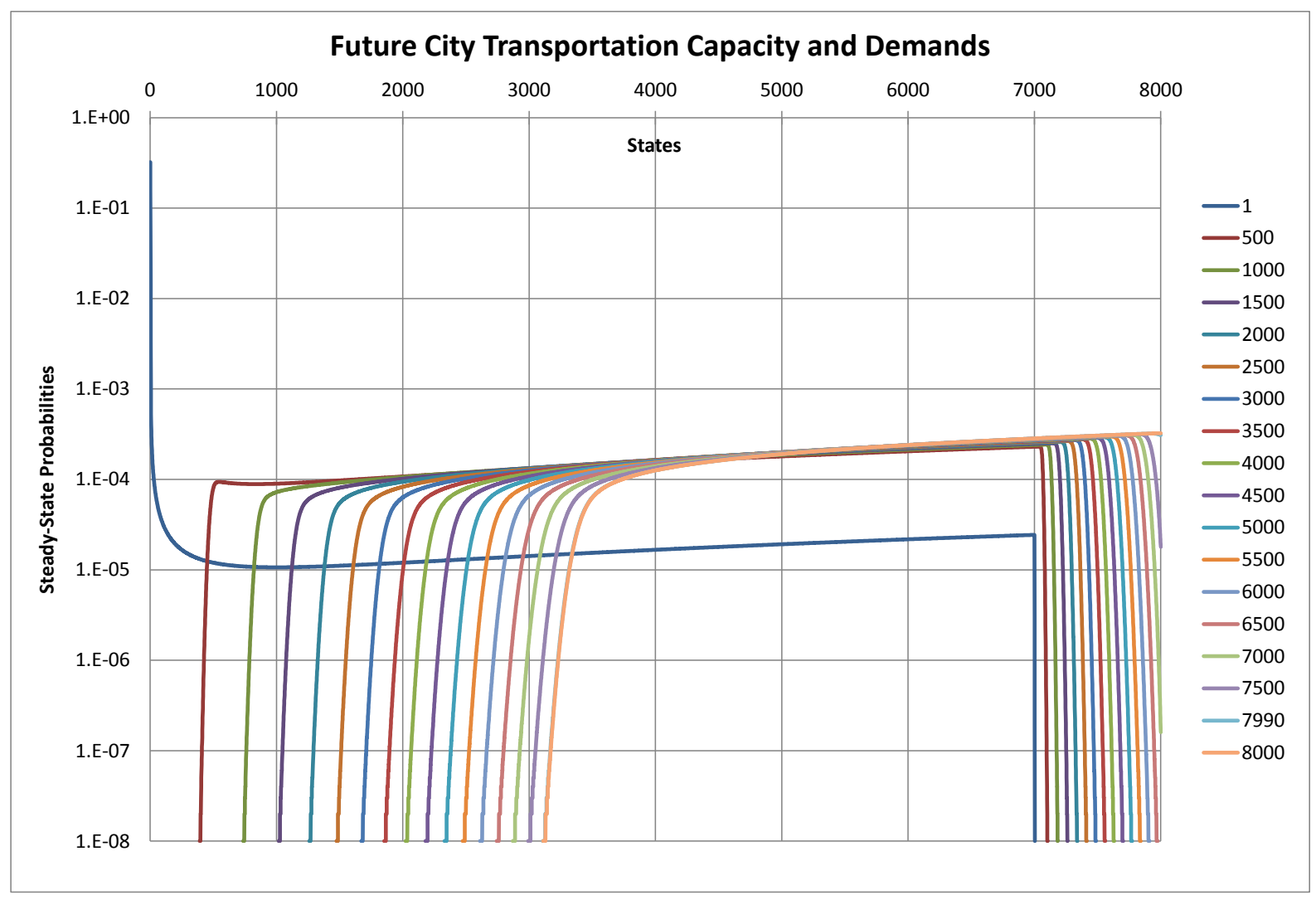

Figure 3 Transportation Capacity, demand, and steady state probabilities (for 18 different scenarios)

Figure 3 visualises all the 18 scenarios that we have considered in this paper. Each scenario is represented by a plot. As before, the horizontal axis is used for the states of the system (a total of 8001 states) and this modelled system is able to provide 8000 vehicles per hour capacity. The vertical axis gives the steady-state probabilities for the city transportation system. Each of the 18 plots gives the probability of the system to be in each of the system states for the particular scenario.

Consider the plot for the lowest-demand case scenario with the transport demand of one vehicle per hour (the bottommost plot in blue colour). The probability for such a system to be in state 0 (idle system) is $32.09 \%$ and to be in state 1 is $32.19 \%$. Note here that state zero means that there is no outstanding vehicle demand in the system. It does not mean that the 
system in this state does not receive a demand for a vehicle. Such cases are possible where there is a high capacity for service and relatively very low demand for jobs. In other words, the system in the lowest demand scenario may remain idle with a high probability, $32.09 \%$, though the service demand may arrive and be satisfied. However, note also that this system, in fact, may remain in state 1 (with one job in the system) with slightly higher probability, $32.19 \%$. The probabilities for this system to be in other states are around $1.0 \mathrm{E}-05$, except for the states 7000 and beyond, where the probability is almost zero (this can be seen by the sharp drop towards the right of the plot and, afterwards, the absence of line).

The scenario for the lowest demand (one vehicle per hour) demonstrates a case of very low demand (e.g., low arrival rate), relatively, compared to a very high capacity (e.g., very high service or departure rate). Such a system is highly likely to be in one of the first two states $(32.09 \%+32.19 \%)$ because the total demand is one vehicle per hour and it may get served as soon as it arrives. Note in the figure a different trend between scenario 1 and all other scenarios. This is due to the fact that the increase in the demand is 500 times $(500=1 \times 500)$ compared to the other scenarios where the highest increase in the demand is 2 times $(1000=500 \times 2)$. That is, each next scenario uses demand with an increase of 500 and therefore, with the increasing demand, each next scenario represents a smaller increase in demand compared to the previous scenario (e.g. $500 / 1500<500 / 1000$ ). Another way to look at it is that for scenario one the system load is almost zero, while scenario 500 represents, relatively, a fair amount of load. We have verified these justifications by solving relevant models and plotting results for models with a linear increase in demand, i.e., 1, 2, 4, 8, 16, and so on. Also consider that the vertical axis is plotted using a logarithmic scale.

The plots for the other transportation demand scenarios represent behaviour similar to the 
system with the demand of 500 vehicles per hour except that the plots shift towards the right with the increase in the demand. While the system with 500 vehicles demand has nonzero probabilities beginning from state 393, the system with 1000 vehicles demand has its first nonzero probability from state 737 . Moreover, the probability values for higher numbered states (7000 and beyond) also increase as can be seen by the delay in the drop of the probabilities towards the right of the plots. The plots for the scenarios with transport demands of 7990 and 8000 vehicles show a continuous increase in probabilities towards the higher numbered state. These two plots, as opposed to all the other plots, do not show a drop towards the right, implying that the system will have the highest probability to be under full load, and therefore would be at risk of not meeting its demand. Such a system is at high risk of reaching instability and this scenario/condition should be avoided. We address this problem in the next section.

\section{Dynamic Configuration of Capacity Sharing}

To further clarify the system behaviour depicted in Figure 3, we note that it is best for the transport system to be in the idle (or near idle) state with the highest probability; as is the case for the lowest demand scenario. However, though such a case represents a low risk of failure, it does also represent a case of low resource utilization and hence wastage of resources. On the other hand, the case of highest demand scenario represents a high risk of failure (e.g., the system may not be able to provide service to its customers and can become unstable), while allowing a high level of utilisation. Transport managers would like the probabilities of the higher numbered states to be zero, implying a low risk of failure. However, they would also like a high level of utilization to justify a higher return on investment (ROI). Our framework allows the practitioners to specify the level of sharing, a precise probability for the system utilisation and risk and provides them with estimates of the required level of capacity. This 
can be done in an automated control manner, and if needed the level of sharing and capacity could be altered based on the real-time demand.

Table 3 (see Appendix, Page 45) lists the probabilities for the last few states of the highest demand scenarios (states 7974 to 8000 of the scenarios with demands of $6000,6500,7000$, 7500,7990 and 8000 vehicles per hour). Note that all the probabilities of the given final states for the scenario with the demand of 6000 vehicles per hour (scenario 6000) are zero. It means that the transport system for this scenario with the total capacity $\left(\mu_{T}\right)$ of 8000 vehicles per hour will comfortably deal with the demand, and will not be at risk of reaching instability or failure. For scenario 6500 , the transport system could be in states 7974 or 7975 with a small probability $1 \mathrm{E}-08$, and with zero probability in states 7976 to 8000 . It implies that the transport system for this scenario will also be able to deal with the associated demand of 6500, and will not become unstable.

The data in Table 3 for the other scenarios can be explained similarly. We focus here on the scenario 8000 (the last column). The data for this scenario shows that the transport system could be in any of these states with a total probability of $0.87 \%(0.000324 \times 27=$ 0.008748). Now suppose that the transport system manager wishes to avoid any risk for the system to reach instability and to achieve this goal the manager looks to provision additional transportation capacity for the system. The model and method to do so are explained in the rest of this section.

Let us generalise Equation (3) into the following equation for transport demand: 


$$
\sum_{1 \leq j \leq m} \lambda_{1}\left(t_{j}\right)+\sum_{1 \leq j \leq m} \lambda_{2}\left(t_{j}\right)+\sum_{1 \leq j \leq m} \lambda_{3}\left(t_{j}\right)+\ldots+\sum_{1 \leq j \leq m} \lambda_{n}\left(t_{j}\right)
$$

where $\lambda_{1}\left(t_{j}\right)$ is the demand for activity one for the time period " $j$ ", $\lambda_{2}\left(t_{j}\right)$ is the demand for activity two for the time period " $j$ ", and so on up to the activity " $n$ " (a finite integer). The time period " $j$ " varies between one and a parameter " $m$ ". The parameter " $m$ " can be selected by the system designers to optimise granularity of control, efficiency, and system complexity. One possibility is to set " $m$ " equals to the number of hours in the day (i.e., 24). So demands will be monitored on an hourly basis and there will be a maximum of 24 demands for activity one; that is; $\lambda_{1}\left(t_{j}\right), 1 \leq j \leq 24$. In this case, the demand for an activity, for a given time period, could be zero or non-zero (consider the demand for e.g. school related transport). The other possibility is to fix the parameter " $m$ " equals to one. In this case, the transport system will be a simpler system but the granularity of control, and hence efficiency, would be limited. Similarly, periods smaller than one hour are also possible, and will provide a higher level of granularity for control and transport operations efficiency (but this depends on the nature of city transport). The total demand of the system given in Equation (6) can be written as

$$
\lambda_{T}=\sum_{1 \leq j \leq m}^{1 \leq i \leq n} \lambda_{i}\left(t_{j}\right)
$$

Similarly, the total transportation capacity of the system can be calculated by Equation (8) below. 


$$
\mu_{T}=\sum_{1 \leq j \leq m}^{1 \leq i \leq n} \mu_{i}\left(t_{j}\right)
$$

where $\mu_{i}\left(t_{j}\right)$ represents the transportation capacity with exponentially distributed service times for activity " $i$ " for the time period " $j$ ". These capacities and demands can be acquired by the system in a distributed and autonomous manner where the sources of the demands and capacities can update the transport system through an API. The quality of the information regarding capacities and demands can be validated through distributed systems technologies such as technologies related to trust. Alternatively, strict authorisation based approaches, or a middle approach can be used based on the specific requirements.

Once the capacities and demands have been specified as above, the transport management system can use a computer algorithm to look for additionally available capacities with mutually exclusive time periods; i.e., the time period " $t_{j}$ " should not be the same for the additional transportation capacity, otherwise it would have already been included in the current transportation capacity. Certainly, there should be a system record for each transportation capacity $\mu_{i}\left(t_{j}\right)$ as to where it is being used for other than their primary purposes. Capacity sharing can be further optimised for various system characteristics or constrains such as cost, sustainability, trust level in the capacity provider, appropriateness of the vehicles for the required purpose, etc. 


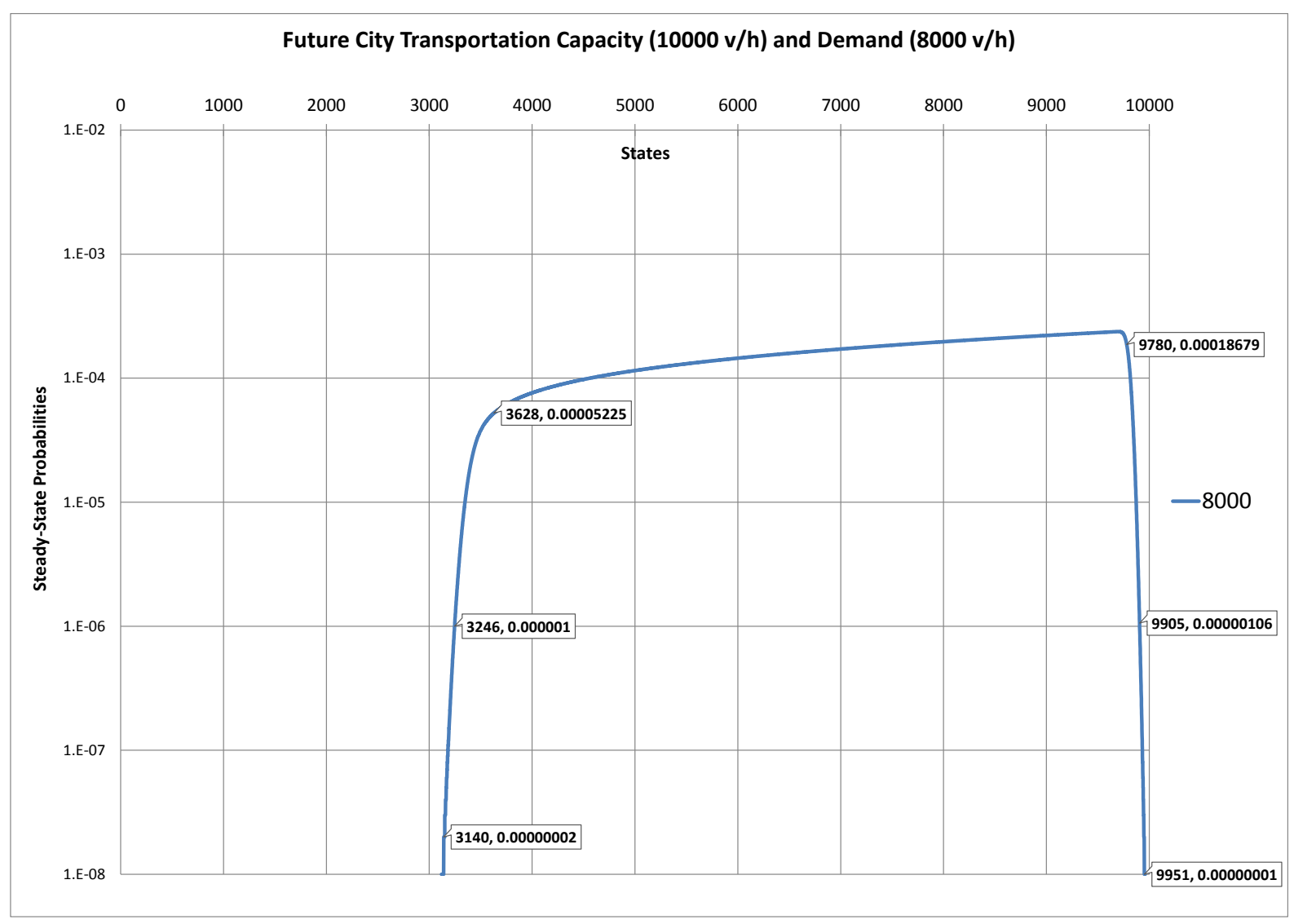

Figure 4 Transportation Capacity, demand, and steady state probabilities (8000/10000 vehicles per hour demand/capacity)

Figure 4 gives the steady-state probabilities for the scenario with transport demand of 8000 vehicles per hour. This is the same scenario as we have discussed earlier in relation to Figure 3. However, this time, the transportation capacity has been increased to 10000 vehicles per hour. Some of the plot values are labelled with the number of states and the associated probabilities. Compare these results with the results for scenario 8000 in Figure 3. For instance, the probability for the system to be in state 9951 is $1.0 \mathrm{E}-08$, while the probabilities for the states numbered 9961 up to 10000, all are zero (shown by the absence of the plot). Note particularly that the probability has gone to zero before state 10000 which implies that the system, whilst providing high resource utilisation, has zero probability for the last few states and therefore this system will not be at risk of instability. 
The additional capacity could be provisioned through sharing, procured through the procedure explained above. The level of transport capacity required to provide stability higher than the original scenario 8000 (Figure 3) was calculated by solving a range of Markov chains with different levels of capacities and a fixed level of demand (8000). This procedure was stopped when a satisfactory level of system stability was found. In this case, the required capacity for the system is 10000 vehicles per hour.

To summarise: the overall system behaviour depicted by Figure 2, Figure 3, and Figure 4 shows that a higher number of vehicle demand will lead to higher probabilities for the system to be under full load. The model provides precise probabilities (we have used double precision number format for higher accuracy of probability values) for the system to be in any of the 8000 states under a range of workloads. We have modelled 18 scenarios, although our approach allows each of the 8000 scenarios to be modelled and their associated precise probabilities to be calculated. Therefore, we can ask such a system to provide answers to questions such as "What transportation capacity should I have in order to meet transportation demands of the city with (e.g.) $80 \%$ probability?". The probabilities used in these queries can be for individual states or aggregated probabilities for multiple states. The Markov model scenarios essentially represent the M/M/C systems.

A smaller figure of 8000 vehicles per hour for transportation capacity is used for explanatory purposes. Any quantity of transportation demand typical of a city can be modelled and numerically solved using the range of techniques that we have developed (see Section “Computational Methods to Solve Large Models" on Page 12). Moreover, our methodology to model the transportation demand of a future city does not depend on the number of 
transportation-related activities in the city (leisure, school etc.); additional sub-demands for new activities can be added to the model.

The approach to computing the numerical solution of the underlying Markov chains allows the practitioner to obtain detailed information about the system as compared to simple analytical results for the number of jobs in the system and response times. The city planners or managers can explore and compute a set of shared capacities that are sufficient, probabilistically, to meet the required transport demands for usual city conditions or a specific situation. Therefore, our framework can be used by the transportation planners and managers to have greater insight into the system and higher efficiencies through a pool of resources that can be shared across various transportation activities in the city; e.g. the transportation capacity for work \& school-related demands in the morning can be used in the evening for shopping \& leisure related transportation demands.

\section{Discussion}

The Markov solution is focused on matching the transport demands (of people and freight mobility) with city transport service provision. This model and its solution were designed to illustrate how sharing transport load in a smart city can improve efficiencies in meeting realtime demand for city services. A smart city environment enables the production and use of such data in the provision of services in these cities. The fast-growing data generated in an online community-like setting is shared across the city network amongst industry, the public and transport-service operators. On the one hand this enables local governments, businesses and other organizations to act smartly by processing the data to provide transport load sharing services that respond to emerging needs within cities; and on the other hand, it allows citizens to take an active role in data sharing with service providers and providing real-time feedback 
on services.

\section{Theoretical contribution}

The paper aims to make a contribution to theory by modelling the potential of the smart city to facilitate a city-network perspective to capacity sharing decision making. This is more efficient than individual firms taking independent decisions, as this often leads to duplication and inefficiency with transport capacity failing to meet volatile and rapidly changing demand.

It is well acknowledged that a large amount of data is generated within smart cities (Manville et al., 2014). However, there is no attempt at exploring the interplay between smart cities, big data, and city logistics sharing. Therefore, we contribute to existing theory on related logistic issues such as RFID tags (Zelbst et al., 2012), information infrastructure capability (SookLing et al., 2015); and administrative data collected directly from citizens, traffic management systems and carbon footprints (Batty, 2013). Although there is a significant body of work at the strategic level, what is missing is the detailed operational implementation of decisions based on big data (analytics).

Moreover, while previous work focuses on the issues of sources and capture (Kitchin, 2014) the issues of volume and velocity are not focused upon theoretically. We go further in our work's analytical scope by providing detailed insight into how big data could be analysed and operationally implemented within the smart city. This will enable more effective capacity decision making. While numerous studies claim to highlight the value of big data (Davenport, 2013), they do not provide operational evidence. 
Whilst the importance of sampling data to make operational decisions is a well-established construct (Taniguchi, 2012), what is less understood are the two main kinds of velocity with respect to big data: (1) the frequency of generation; and, (2) frequency of handling, recording, and publishing. Our smart city operations model mediates the role of velocity on system performance (Leonardi, 2012). Furthermore, we also extend fairly simplistic considerations of data veracity. This is achieved by indicating the risks and challenges its complexity poses to effective operational decision making (the significant differences in its coverage, accuracy, and timeliness). For instance, one cannot assume, as is often outlined in leading works (Kitchin, 2014), that collecting more data will automatically correlate with a better performing operational model.

Previous attempts to model big data logistics have been based on empirical data gathered from small sample sizes (Fosso-Wamba et al., 2015; Taniguchi, 2012). These and other works omit theoretical considerations of the variety dimension. Through our Markovian analysis of aggregated structured and unstructured data, we worked with data collected from a population $(\mathrm{n}=\mathrm{all})$ rather than a sample and therefore the developed model both focuses and is built on data variety.

In addition, our work complements that of Fosso-Wamba et al., (2015) and Setia and Patel (2013), who explore the role of big data in building operational capabilities and the absorptive capacity of logistic operations. Their research findings underscore the importance of integrating big data into city logistics design. They argue for greater integration between big data and $\mathrm{OM}$ and encourage advancing new theories at the big data-OM interface. We are therefore extending the adoption literature to the sub-field of big data and city logistics research. Through this modelling study, we are building new knowledge on the inter- 
relationships between big data capabilities, load sharing, absorptive capacity and city transport planning capabilities.

We have endeavoured to provide a new understanding of load sharing and optimization in a smart city context. Specifically through demonstrating how big data could be used to improve operational efficiency in meeting demand and also lowering over-capacity. The work suggests how improvement could take place by having a $\left(\right.$ private $\left.^{1}\right)$ car free city environment with autonomous vehicles and shared resource capacity among providers. Although researchers have begun to assess OAC capabilities of big data, their antecedents are still not well examined.

\section{Implications for smart city operations practitioners}

The developments in technologies such as $4 \mathrm{G}$ wireless, FTTX (Fibre to the $\mathrm{x}$ ), IoT, mobile computing, cloud computing and big data are enabling new design models of future city operations systems. Smart city practitioners must make the best use of these emerging technologies to improve their operational efficiency and environmental performance. The city logistics aspects point to how transportation would actually need to be re-organized so as to deal with the $\mathrm{CO}_{2}$ footprint.

Big data is typically seen by the private sector as an enhanced form of business intelligence or enhanced data analytics capability (Kitchin, 2014). However, the model proposed here is embedded in the operational sharing economy (Li et al., 2015) and this paper could be seen in the applied sense, as a move from individual firms optimizing their own transportation supply

\footnotetext{
${ }^{1}$ It is possible that future cities will continue to allow people to own autonomous cars but we believe that technology will allow the creation of micro-services which will be available dynamically with almost zero human (visible) intervention and administrative time. This will allow people to rent cars and avoid parking and other disadvantages of owning cars.
} 
to a shared collaborative load system. As MIT's (Caplice, 2015) recently noted in the Wall Street Journal such ideas are radical changes for practitioners and are driven by the growth of the sharing economy and the trend away from scale economies based on global systems to more decentralized local transport solutions.

Power and governance in such a system would be transferred more to the city authorities, public organizations and local citizens away from profit-driven individual firms (Taniguchi, 2012). Third party logistics firms operating as 'last mile' delivery operators within the city boundary would in a sense lose business unless they could encompass the sharing economy. They would also need to be willing to share business intelligence, their freight capacity and utilize the shared network offerings. These changed interaction patterns would, therefore, transform current city network actor interaction systems, with geography increasing the impact on interaction decisions.

Barton and Court (2012) highlighted that the key OM challenge for smart city practitioners in using big data is to ensure that it is trustworthy and understandable for all their employees. Shah and Pathak (2014) for example, suggests that advanced business analytics skills are still largely confined to an expert level. In order to add value from using big data, it is, therefore, essential that all levels of practitioners are well equipped to make crucial strategic and operations decisions using big data (which can be only be achieved through specialist training). Similarly, while organisations might have access to reliable information, owing to the lack of clear and coherent content, practitioners could find it difficult to locate this properly as/when needed. 
Smart city practitioners need to emphasize the finding of the right skills including technical, analytical, governance skills and networked relationships if they are to optimize their implementation of big data (Schroeck et al., 2012). As argued by McAfee et al., (2012) the enormous amount of big data requires cleaning and organising, which necessitates recruiting technically and analytically sound data scientists. Practitioners should make sure that smart city data scientists are well conversant about business and governances issues and the necessary skills to talk in the language of business. The findings show that data scientists should be trained to build networked relationships which are an important skill (Davenport, 2014). As such, practitioners should grow, nurture and retain their smart city data scientists in order to grasp regular opportunities. Another challenge of using big data for practitioners is to develop both their technology infrastructure and business processes in the initial phase (Batty, 2013). To strengthen this aspect of personnel expertise capability, an organized effort must be made to build technical knowledge, technological management knowledge, business knowledge and relational knowledge related to big data logistics (Fosso-Wamba et al., 2015).

This study also urges practitioners to ensure safe handling of individual and organizational privacy in the context of big data. For example, keeping individual and business customer name, address, market, operational and financial information confidential and undisclosed to third parties. This poses an enormous challenge for big data logistics (Kitchin, 2014). In this regard, McAfee and Brynjolfsson (2012) highlighted that the privacy concern is becoming more significant in this environment and should receive greater attention.

\section{Implications for Future Cities' Supply Chain Management}


The successful modelling of the Markov model in this study is premised on a big data operations framework which celebrates an enhanced interconnectivity between its components. It is assumed that customers, information management infrastructure, and transport services would share in a mutually supportive reciprocity. This smart cities transportation strategy thus introduces contextual discontinuity in the sphere of operations management. This new contextual environment calls for greater collaboration and integration between the system's actors for its effective functioning. From an operations management perspective, this calls for greater emphasis on supply chain integration (SCI) (Prajogo and Olhager, 2012), particularly given that this scenario affords the operations managers limited direct control over information and transportation assets, if companies are to reap the benefits of the big data resources and more specifically the notion of load sharing as these would be controlled by a third party, the city manager. Nevertheless, we share the conviction that upto-date information about transportation capacity and demand could potentially be a valuable asset to firms and could be used in enhanced logistics planning (Foresti et al., 2015; RuizTorres and Nakatani, 1998) to provide customised solutions based on the specificities of individual cities. Furthermore, updated information on an hourly basis could potentially be integrated into logistics activities to respond to fluctuations in transport capacity in real time and thus provide flexibility and greater supply chain agility (Zhang et al., 2011). However, the real challenge lies in procuring and managing this intelligence in the context of this new “smart cities landscape" (Angelidou, 2014).

Contingency theory suggests that an organization must be aligned with its internal as well as external environment to achieve optimal performance (Chong and Rundus, 2004; Hayes, 1977, p. 19). Thus, applied to SCI, contingency theory suggests that the individual dimensions of SCI should be aligned, in order to achieve the best performance. In terms of 
external fit, the contingency theory indicates the need for consistency between an organizational structure and the strategy it pursues in response to its external environment (Flynn et al., 2010). At an operational level, this means that a manufacturer should respond to changes in its external environment by developing, selecting and implementing strategies to maintain fit (Kotha and Nair, 1995; Tushman and Nadler, 1978). Therefore, in the context of smart cities transportation solutions based on the framework presented, we predict the need for greater integration of third party logistics (Birou et al., 2011).

Whilst the practice of integrating third party logistics in the focal firm's supply chain is not new the unique contextual features of future cities, in particular, the introduction of the city manager variable, puts an accentuated emphasis on relational capital (Chen and Hung, 2014; Li et al., 2014). In this scenario, the implication for future supply chain management is that efficient operations would depend on the ability of managers to build effective collaborations with the transport/logistics provider, other firms in the supply chain, as well as the city manager in order to harness value from the big data information. Therefore, in this new domain, relationship and trust building (Prajogo and Olhager, 2012) would probably take centre stage. This is because, this new way of functioning would require a high degree of openness (Gunasekaran et al., 2007) of potentially sensitive operations activities involving a high level of information sharing, and in all likelihood, frequent and intense communication between firms, transport/logistics provider and city managers. In effect, in addition to third party logistics integration, information integration (Cagliano et al., 2006) would also feature prominently as a determinant of an organization's supply chain performance in the context of future cities. Therefore, the contingencies created by a smart city transportation environment would impose on operations management the need for greater and perhaps more sophisticated 
integration of logistics and information. However, alignment with this external environment would also have implications for the internal workings of supply chains.

The implications for the internal alignment of future operations management can be viewed through the lens of IT-enabled supply chain (Rai et al., 2006). Because the imperative of sharing at the heart of external fit, any internal changes would need to share the same philosophy. Under the banner of IT-enabled supply chain, previous work has indeed accentuated the importance of communication and application of IT in supply chain management (SCM) (Gunasekaran and Ngai, 2004) for the purpose of supply chain integration. For example, (Rai et al., 2006) offer a model that examines how IT infrastructure could be usefully leveraged to harness value from information integration and hence improve supply chain process integration leading to superior firm performance.

The work of (Prajogo and Olhager, 2012) is also pertinent to this conversation. In this work, the authors show that two aspects of information integration namely, IT capabilities for connectivity and information sharing, have positive effects on logistics integration. As we have argued, a smart city's transportation solution based on big data resources brings with it a shift in the operational paradigm towards a more collaborative modus operandi (Clegg et al., 2013). Thus, the implication for supply chain integration from an internal alignment perspective of contingency theory potentially resides in how to leverage IT resources in building more transparent supply chains which are based on meaningful and trustworthy relationships while preserving economic viability. It is interesting that (Prajogo and Olhager, 2012: 519) observed a low correlation between IT capabilities and information sharing which suggests "that firms cannot assume that because they are technically connected, they are also 
socially connected." Whilst it is unequivocal that IT capabilities integration would have a defining role in a future cities supply chain management context, we agree with (Rai et al., 2006) that this would need to be complemented by the integration of other relationship management capabilities in order to extract value from the unique big data environment discussed in this work. Therefore, while smart cities might well epitomise the frontier of technological innovations applications in addressing future cities needs, including transportation, future solutions might well be rooted in a distinctively human judgement, that is, trust.

\section{Conclusions}

The initial research aim of this paper was to investigate how big data is transforming smart city transport operations. In meeting this aim, the research relied on Markov modelling and numerical solutions. There are risks and challenges with smart city operations and big data (Kaplan \& Mikes, 2012). Even bearing this in mind, as the prominence of big data continues to develop and stakeholder groups become increasingly knowledgeable and engaged, there is considerable incentives for operations managers to achieve value added improvement (FossoWamba et al., 2015). This could be through transforming their operations models from transactional to sharing systems and the extracting of new forms of operational value from the big data (Li et al., 2015).

The networking technologies such as FTTX and LTE are enabling fast access to remote computational and storage resources, allowing operators to share data in near real-time. This is in contrast to the past where several data islands existed and access to these data islands were slow or non-existent. This hindered synchronisation, sharing and use of data for multiple purposes across and between various city management related systems (Mehmood et 
al., 2015). IoT and sensor networking technologies will provide the logistics pulse of future cities. It will allow future cities to be monitored and controlled in real time. Mobile computing is allowing computing intensive tasks to take place on small devices that we carry around and the devices that are embedded in our static and mobile environments. Cloud computing is enabling computing to be provided as an on-demand elastic utility accessible through any device and with minimal management effort. New hardware architectures such as GPUs, Field-Programmable Gate Array (FPGA) and Cell Broadband Engine Architecture (Cell BE) are providing huge amount of computational power for us to solve increasingly large OM problems (Mehmood and Lu, 2011). Furthermore, the emerging computational units are much more reconfigurable today compared to the single core machines of the past, although the complexity of the design space for software developers is also increasing. All these technologies have given rise to big data, its associate challenges, as well as providing opportunities to address those challenges. We believe that modelling realistic, complex and large smart city- problems require significantly advanced big data computational intelligence which is possible today due to the advancements in computations, both hardware and software. However, significant efforts are required to translate raw computational power into operational intelligence.

Notwithstanding, operational intelligence on its own has little value in solving future cities problems unless it can be leveraged into useful capabilities. We have argued from the vantage point of future cities supply change management emphasising that the growth in the sharing economy would change the dynamics of supply chain operations. In a smart cities landscape, firms would need to maintain external and internal alignment (Gonzalez-Benito and Lannelongue, 2014). Against a backdrop of the transportation solution presented, this would translate in greater integration of the operational intelligence in the form of logistics and 
information in the focal firm supply chain. However, our analysis shows that in spite of the coming of age of technological solutions in the smart cities context, and in spite of the predictive proclivities of the Markov process, it would be ill-advised to ignore the significance of the flesh of blood cosmopolitans of future cities. In fact, in this new city landscape, high-value social relationships ("Editorial," 2005) might well be viewed as complementary resources to technological infrastructure in forging future cities supply chain management capabilities.

More in-depth analysis and more discrete modelling are clearly needed to assist in the implementation of big data initiatives. Some of the changes that operations and their connected logistic chains face are revolutionary and this requires careful consideration from both a practical and theoretical point of view. To advance this Markovian work, three types of research are urgently needed to extend our preliminary results. Firstly, intensive case studies of the transformation of traditional city logistic systems and the development of new big data operations models. These need to be identified and documented. The description of the new models and the rich context in which these new models are embedded will provide a deep insight to researchers and practitioners in exploring similar opportunities and challenges in their own domains.

Secondly, new analytical frameworks, tools and techniques need to systematically capture relevant data and generate reliable insights to inform operational and strategic decision making of operations managers (Slack and Lewis, 2011). Some existing frameworks and tools can be adapted for big data but new ones need to be developed to address emerging opportunities. 
Thirdly and perhaps most importantly, is new theoretical and empirical research about the transformation of traditional city operations models and the emergence of new ones in the big data space. Big data provides the ideal environment for a range of new innovations at the interface between big data and operational activity.

This paper coupled with our earlier work on the solution of large Markov models provides a promising approach for big data technologies and solutions. Whilst we have primarily addressed the volume and velocity challenges, through intelligent storage and parallel computing techniques, we need also to aim to explore the value, veracity and variety challenges of big data.

\section{Acknowledgement}

The software used for the modelling and numerical solution in this paper is executed on the Aziz supercomputer at King AbdulAziz University, Jeddah, Saudi Arabia. 


\section{Appendix}

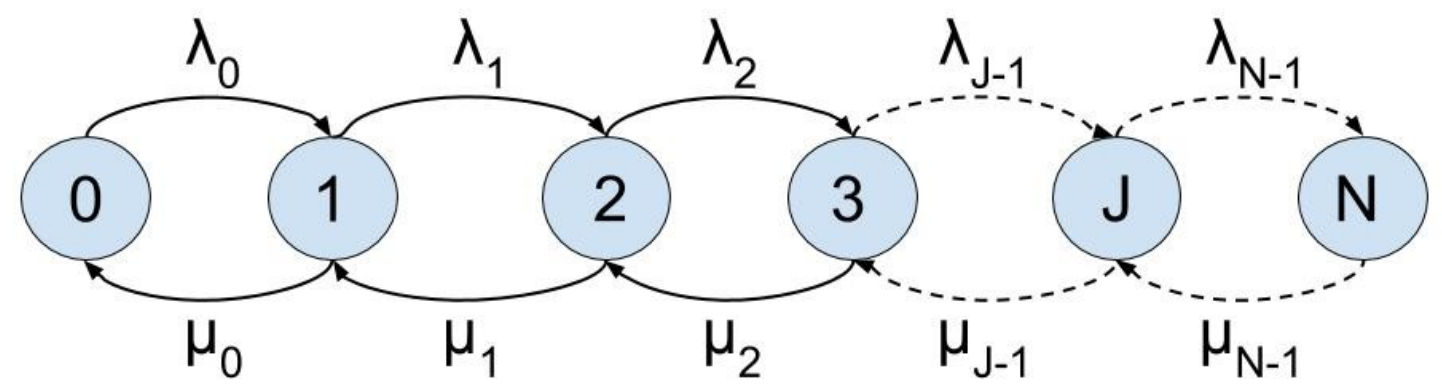

Figure 5 The (generic) Transition Diagram for the CTMC of the transport model

Table 2 The Generator Matrix Q (transition rate matrix) of the CTMC depicted in Figure 5

\begin{tabular}{|c|c|c|c|c|c|c|c|}
\hline$-\lambda$ & $\lambda$ & 0 & $\cdots$ & $\ldots$ & $\ldots$ & $\ldots$ & $\cdots$ \\
\hline$\mu$ & $-(\mu+\lambda)$ & $\lambda$ & 0 & $\cdots$ & $\cdots$ & $\cdots$ & $\cdots$ \\
\hline 0 & $2 \mu$ & $-(2 \mu+\lambda)$ & $\lambda$ & 0 & $\cdots$ & $\cdots$ & $\ldots$ \\
\hline 0 & 0 & $3 \mu$ & $-(3 \mu+\lambda)$ & $\lambda$ & 0 & $\ldots$ & $\ldots$ \\
\hline$\vdots$ & $\vdots$ & $\ldots$ & $\ldots$ & $\because$ & $\cdots$ & $\ldots$ & $\cdots$ \\
\hline$\vdots$ & $\vdots$ & $\vdots$ & $\cdots$ & $\cdots$ & $\because$ & $\ldots$ & $\cdots$ \\
\hline 0 & $\vdots$ & $\vdots$ & $\vdots$ & 0 & $b \mu$ & $-(b \mu+\lambda)$ & $\lambda$ \\
\hline 0 & 0 & $\ldots$ & $\ldots$ & $\ldots$ & 0 & $c \mu$ & $-(c \mu)$ \\
\hline
\end{tabular}



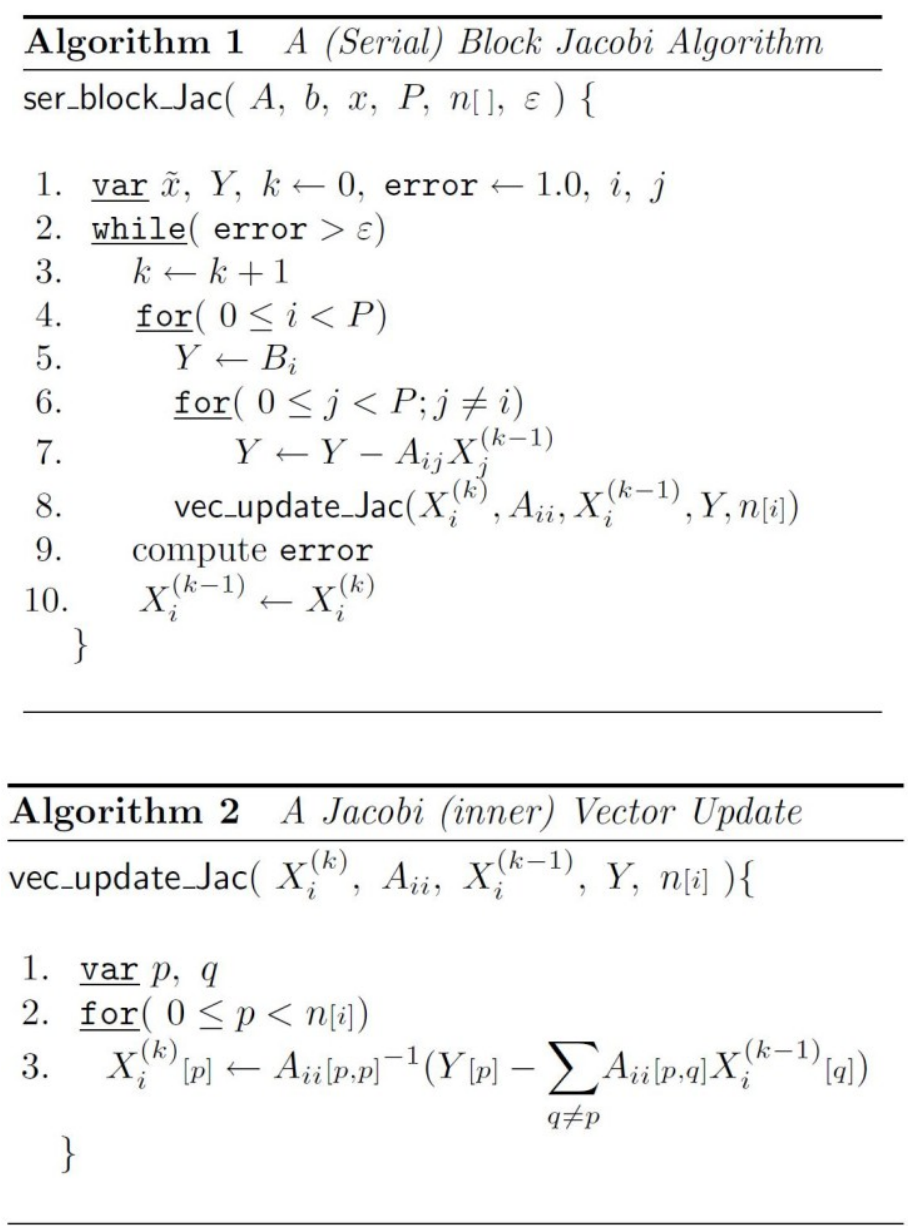

Figure 6 Jacobi Algorithm for solving Markov Chains 
Table 3 Probabilities for the last few states of the highest demand scenarios (states 7974 to 8000)

\begin{tabular}{|c|c|c|c|c|c|c|}
\hline state & 6000 & 6500 & 7000 & 7500 & 7990 & 8000 \\
\hline 7974 & 0 & $1 \mathrm{E}-08$ & $2.15 \mathrm{E}-06$ & $6.54 \mathrm{E}-05$ & 0.000318 & 0.000324 \\
\hline 7975 & 0 & $1 \mathrm{E}-08$ & $1.98 \mathrm{E}-06$ & $6.3 \mathrm{E}-05$ & 0.000318 & 0.000324 \\
\hline 7976 & 0 & 0 & $1.83 \mathrm{E}-06$ & $6.06 \mathrm{E}-05$ & 0.000317 & 0.000324 \\
\hline 7977 & 0 & 0 & $1.68 \mathrm{E}-06$ & $5.82 \mathrm{E}-05$ & 0.000317 & 0.000324 \\
\hline 7978 & 0 & 0 & $1.55 \mathrm{E}-06$ & $5.59 \mathrm{E}-05$ & 0.000317 & 0.000324 \\
\hline 7979 & 0 & 0 & $1.42 \mathrm{E}-06$ & $5.36 \mathrm{E}-05$ & 0.000317 & 0.000324 \\
\hline 7980 & 0 & 0 & $1.31 \mathrm{E}-06$ & $5.14 \mathrm{E}-05$ & 0.000316 & 0.000324 \\
\hline 7981 & 0 & 0 & $1.2 \mathrm{E}-06$ & 4.92E-05 & 0.000316 & 0.000324 \\
\hline 7982 & 0 & 0 & $1.09 \mathrm{E}-06$ & 4.71E-05 & 0.000316 & 0.000324 \\
\hline 7983 & 0 & 0 & $1.0 \mathrm{E}-06$ & $4.51 \mathrm{E}-05$ & 0.000316 & 0.000324 \\
\hline 7984 & 0 & 0 & $9.1 \mathrm{E}-07$ & $4.31 \mathrm{E}-05$ & 0.000315 & 0.000324 \\
\hline 7985 & 0 & 0 & 8.3E-07 & 4.11E-05 & 0.000315 & 0.000324 \\
\hline 7986 & 0 & 0 & $7.6 \mathrm{E}-07$ & $3.92 \mathrm{E}-05$ & 0.000315 & 0.000324 \\
\hline 7987 & 0 & 0 & $6.9 \mathrm{E}-07$ & $3.74 \mathrm{E}-05$ & 0.000314 & 0.000324 \\
\hline 7988 & 0 & 0 & $6.2 \mathrm{E}-07$ & $3.56 \mathrm{E}-05$ & 0.000314 & 0.000324 \\
\hline 7989 & 0 & 0 & $5.6 \mathrm{E}-07$ & $3.38 \mathrm{E}-05$ & 0.000314 & 0.000324 \\
\hline 7990 & 0 & 0 & $5.1 \mathrm{E}-07$ & $3.21 \mathrm{E}-05$ & 0.000314 & 0.000324 \\
\hline 7991 & 0 & 0 & 4.6E-07 & $3.05 \mathrm{E}-05$ & 0.000313 & 0.000324 \\
\hline 7992 & 0 & 0 & 4.1E-07 & $2.89 \mathrm{E}-05$ & 0.000313 & 0.000324 \\
\hline 7993 & 0 & 0 & $3.7 \mathrm{E}-07$ & $2.74 \mathrm{E}-05$ & 0.000313 & 0.000324 \\
\hline 7994 & 0 & 0 & $3.3 \mathrm{E}-07$ & $2.59 \mathrm{E}-05$ & 0.000312 & 0.000324 \\
\hline 7995 & 0 & 0 & $3.0 \mathrm{E}-07$ & $2.44 \mathrm{E}-05$ & 0.000312 & 0.000324 \\
\hline 7996 & 0 & 0 & $2.6 \mathrm{E}-07$ & $2.3 \mathrm{E}-05$ & 0.000311 & 0.000324 \\
\hline 7997 & 0 & 0 & $2.3 \mathrm{E}-07$ & $2.17 \mathrm{E}-05$ & 0.000311 & 0.000324 \\
\hline 7998 & 0 & 0 & $2.1 \mathrm{E}-07$ & $2.04 \mathrm{E}-05$ & 0.000311 & 0.000324 \\
\hline 7999 & 0 & 0 & $1.8 \mathrm{E}-07$ & $1.92 \mathrm{E}-05$ & 0.00031 & 0.000324 \\
\hline 8000 & 0 & 0 & $1.6 \mathrm{E}-07$ & $1.8 \mathrm{E}-05$ & 0.00031 & 0.000324 \\
\hline
\end{tabular}




\section{Reference}

Ahmad, N., Mehmood, R., 2015. Enterprise systems: are we ready for future sustainable cities. Supply Chain Manag. Int. J. 20, 264-283. doi:10.1108/SCM-11-2014-0370

Alazawi, Z., Abdljabar, M.B., Altowaijri, S., Vegni, A.M., Mehmood, R., 2012. ICDMS: an intelligent cloud based disaster management system for vehicular networks, in: Communication Technologies for Vehicles. Springer Berlin Heidelberg, pp. 40-56.

Alazawi, Z., Alani, O., Abdljabar, M.B., Altowaijri, S., Mehmood, R., 2014a. A smart disaster management system for future cities, in: Proceedings of the 2014 ACM International Workshop on Wireless and Mobile Technologies for Smart Cities. ACM, pp. 1-10.

Alazawi, Z., Alani, O., Abdljabar, M.B., Mehmood, R., 2014b. Transportation Evacuation Strategies Based on VANET Disaster Management System. Procedia Econ. Finance 18, 352-360.

Alazawi, Z., Altowaijri, S., Mehmood, R., Abdljabar, M.B., 2011. Intelligent disaster management system based on cloud-enabled vehicular networks, in: ITS Telecommunications (ITST), 2011 11th International Conference on. IEEE, pp. 361368.

Allwinkle, S., Cruickshank, P., 2011. Creating smart-er cities: An overview. J. Urban Technol. $18,1-16$.

Anderson, D., Sweeney, D., Williams, T., Camm, J., Cochran, J., 2013. Statistics for Business \& Economics. Cengage Learning.

Angelidou, M., 2014. Smart city policies: A spatial approach. Cities 41, S3-S11.

Ayres, G., Mehmood, R., 2009. On Discovering Road Traffic Information Using Virtual Reality Simulations, in: Proceedings of the UKSim 2009: 11th International Conference on Computer Modelling and Simulation, UKSIM '09. IEEE Computer Society, Washington, DC, USA, pp. 411-416. doi:10.1109/UKSIM.2009.14

Barton, D., Court, D., 2012. Making advanced analytics work for you. Harv. Bus. Rev. 90, 7883.

Batty, M., 2013. Big data, smart cities and city planning. Dialogues Hum. Geogr. 3, 274-279. doi:10.1177/2043820613513390

Batty, M., 2012. Editorial Smart cities, big data. Environ. Plan. B Plan. Des. 39, 191 - 193. doi:10.1068/b3902ed

Biederman, D., 2013. Big data. Journal of Commerce. J. Commer. 14, 82-87.

Bielinski, S.J., Olson, J.E., Pathak, J., Weinshilboum, R.M., Wang, L., Lyke, K.J., Ryu, E., Targonski, P.V., Van Norstrand, M.D., Hathcock, M.A., Takahashi, P.Y., McCormick, J.B., Johnson, K.J., Maschke, K.J., Rohrer Vitek, C.R., Ellingson, M.S., Wieben, E.D., Farrugia, G., Morrisette, J.A., Kruckeberg, K.J., Bruflat, J.K., Peterson, L.M., Blommel, J.H., Skierka, J.M., Ferber, M.J., Black, J.L., Baudhuin, L.M., Klee, E.W., Ross, J.L., Veldhuizen, T.L., Schultz, C.G., Caraballo, P.J., Freimuth, R.R., Chute, C.G., Kullo, I.J., 2014. Preemptive genotyping for personalized medicine: design of the right drug, right dose, right time-using genomic data to individualize treatment protocol. Mayo Clin. Proc. 89, 25-33. doi:10.1016/j.mayocp.2013.10.021

Birou, L., Germain, R.N., Christensen, W.J., 2011. Applied logistics knowledge impact on financial performance. Int. J. Oper. Prod. Manag. 31, 816-834.

Blanco, E.E., Fransoo, J.C., 2013. Reaching 50 million nanostores: retail distribution in emerging megacities. Research School for Operations Management and Logistics. Working Paper, BETA Research School. 
Bram, J., Ludvigson, S.C., 1998. Does consumer confidence forecast household expenditure? A sentiment index horse race. Econ. Policy Rev. 4.

Bruner, J., 2015. Defining the industrial Internet - O'Reilly Radar [WWW Document]. URL http://radar.oreilly.com/2013/01/defining-the-industrial-internet.html (accessed 9.1.15).

Burnson, P., 2013. New Study Released at CSCMP Addresses "Big Data. Supply Chain Manag. Rev. 17, 76-78.

Büscher, M., Coulton, P., Efstratiou, C., Gellersen, H., Hemment, D., Mehmood, R., Sangiorgi, D., 2009. Intelligent Mobility Systems: Some Socio-technical Challenges and Opportunities, in: Mehmood, R., Cerqueira, E., Piesiewicz, R., Chlamtac, I. (Eds.), Communications Infrastructure. Systems and Applications in Europe, Lecture Notes of the Institute for Computer Sciences, Social Informatics and Telecommunications Engineering. Springer Berlin Heidelberg, pp. 140-152.

Cagliano, R., Caniato, F., Spina, G., 2006. The linkage between supply chain integration and manufacturing improvement programmes. Int. J. Oper. Prod. Manag. 26, 282-299.

Caplice, C., 2015. Chris Caplice, Matthew Rose on What U.S. Supply Chains Need. Wall Str. J.

Caragliu, A., Bo, C.D., Nijkamp, P., 2011. Smart Cities in Europe. J. Urban Technol. 18, 65-82. doi:10.1080/10630732.2011.601117

Carroll, C.D., Fuhrer, J.C., Wilcox, D.W., 1994. Does consumer sentiment forecast household spending? If so, why? Am. Econ. Rev. 1397-1408.

Chen, P.-C., Hung, S.-W., 2014. Collaborative green innovation in emerging countries: a social capital perspective. Int. J. Oper. Prod. Manag. 34, 347-363.

Chong, V.K., Rundus, M.J., 2004. Total quality management, market competition and organizational performance. Br. Account. Rev. 36, 155-172.

Clegg, J.M., Prasanta Dey, B., Clegg, B., Wan, Y., 2013. Managing enterprises and ERP systems: a contingency model for the enterprization of operations. Int. J. Oper. Prod. Manag. 33, 1458-1489.

Davenport, T.H., 2014. How strategists use "big data" to support internal business decisions, discovery and productionnull. Strategy Leadersh. 42, 45-50. doi:10.1108/SL-052014-0034

Davenport, T.H., 2013. Analytics 3.0. Harv. Bus. Rev. 91, 64-+.

Editorial, 2005. . Int. J. Oper. Prod. Manag. 25, 401-402.

Elmirghani, J.M., Badic, B., Liu, Y., Mehmood, R., Wang, C., Xing, W., Zuaxola, I., Jone, S., 2006. IRIS: An Intelligent Radio-Fibre Telematics System. Proc. 13th ITS WORLD Congr. Lond. 8-12 Oct. 2006.

Flynn, B.B., Huo, B., Zhao, X., 2010. The impact of supply chain integration on performance: A contingency and configuration approach. J. Oper. Manag. 28, 58-71.

Foresti, G.L., Farinosi, M., Vernier, M., 2015. Situational awareness in smart environments: socio-mobile and sensor data fusion for emergency response to disasters. J. Ambient Intell. Humaniz. Comput. 6, 239-257.

Fosso-Wamba, S., Akter, S., Edwards, A., Chopin, G., Gnanzou, D., 2015. How "big data"can make big impact: Findings from a systematic review and a longitudinal case study. Int. J. Prod. Econ. 165, 234-246.

Freeman, J., Burdon, J., 2013. The use of simulation in operations management: a survey. Int. Simul. Gaming Res. Yearb. Simul. Games Emerg. Crisis Manag. 174.

Freeman, J., Parra-Frutos, I., Science, U. of M.I. of, Management; , T. (United K.M.S. of, 2000. The Impact of Different Arrival Patterns on Queuing Systems when Customers are 
Impatient. Manchester School of Management, University of Manchester, Institute of Science \& Technology.

Garrett, T.A., 2003. Aggregated versus disaggregated data in regression analysis: implications for inference. Econ. Lett. 81, 61-65.

Gonzalez-Benito, J., Lannelongue, G., 2014. An integrated approach to explain the manufacturing function's contribution to business performance. Int. J. Oper. Prod. Manag. 34, 1126-1152.

Goodfriend, M., 1992. Information-aggregation bias. Am. Econ. Rev. 508-519.

Graham, G., Mehmood, R., Coles, 2015. Exploring future cityscapes through urban logistics prototyping: a technical viewpoint. Supply Chain Manag. Int. J. 20, 341-352. doi:10.1108/SCM-05-2014-0169

Gue, K., 2014. The Social Implications of Crowdsourced Delivery.

Gunasekaran, A., Ngai, E.W., 2004. Information systems in supply chain integration and management. Eur. J. Oper. Res. 159, 269-295.

Gunasekaran, A., Sharif, A.M., Irani, Z., Lloyd, D., 2007. Information technology and performance management for build-to-order supply chains. Int. J. Oper. Prod. Manag. 27, 1235-1253.

Hayes, D.C., 1977. The contingency theory of managerial accounting. Account. Rev. 22-39.

James, M., Michael, C., Brad, B., Jacques, B., 2011. Big data: The next frontier for innovation, competition, and productivity. McKinsey Glob. Inst.

Kaplan, R.S., Mikes, A., 2012. Managing risks: A new framework. Harv. Bus. Rev. 90, 48-60.

Kitchin, R., 2014. Big Data, new epistemologies and paradigm shifts. Big Data Soc. 1, 2053951714528481. doi:10.1177/2053951714528481

Kotha, S., Nair, A., 1995. Strategy and environment as determinants of performance: evidence from the Japanese machine tool industry. Strateg. Manag. J. 16, 497-518.

Kural, D., Billens, P., 2015. Big data and analytics, counterparty credit risk management. IBM.

Kwiatkowska, M., Mehmood, R., 2002. Out-of-core solution of large linear systems of equations arising from stochastic modelling, in: Process Algebra and Probabilistic Methods: Performance Modeling and Verification. Springer Berlin Heidelberg, pp. 135-151.

Kwiatkowska, M., Mehmood, R., Norman, G., Parker, D., 2002. A symbolic out-of-core solution method for Markov models. Electron. Notes Theor. Comput. Sci. 68, 589604.

Kwiatkowska, M., Norman, G., Parker, D., 2011. PRISM 4.0: Verification of probabilistic realtime systems, in: Computer Aided Verification. Springer, pp. 585-591.

Kwiatkowska, M., Parker, D., Y., Z., Mehmood, R., 2004. Dual-Processor Parallelisation of Symbolic Probabilistic Model Checking, in: In Proc. 12th International Symposium on Modelling, Analysis, and Simulation of Computer and Telecommunication Systems, MASCOTS'04. IEEE Computer Society Press, p. DOI-10.

Leonardi, P.M., 2013. Theoretical foundations for the study of sociomateriality. Inf. Organ. 23, 59-76.

Leonardi, P.M., 2012. Materiality, sociomateriality, and socio-technical systems: what do these terms mean? How are they related? Do we need them? Mater. Organ. Soc. Interact. Technol. World 25-48. 
Lierow, M., 2014. B2City: the next wave of urban logistics [WWW Document]. URL http://www.supplychain247.com/paper/b2city_the_next_wave_of_urban_logistics (accessed 2.14.15).

Li, F., Roden, S., Nucciarelli, A., Graham, G., 2015. How Smart Cities Transform Operations Models: A New Research Agenda for Operations Management in the Digital Economy. Prod. Plan. Control.

Li, Y., Ye, F., Sheu, C., 2014. Social capital, information sharing and performance: Evidence from China. Int. J. Oper. Prod. Manag. 34, 1440-1462.

Manville, C., Cochrane, G., Cave, J., Millard, J., Pederson, J.K., Thaarup, R.K., Liebe, A., Wissner, M., Massink, R., Kotterink, B., 2014. Mapping Smart Cities in the EU [WWW Document]. URL http://www.rand.org/pubs/external_publications/EP50486.html (accessed 9.1.15).

Manyika, J., Chui, M., Brown, B., Bughin, J., Dobbs, R., Roxburgh, C., Byers, A.H., 2011. Big data: The next frontier for innovation, competition, and productivity.

McAfee, A., Brynjolfsson, E., 2012. Big Data: The Management Revolution. Harv. Bus. Rev. 90, 60-6, 68, 128.

McAfee, A., Brynjolfsson, E., Davenport, T.H., Patil, D.J., Barton, D., 2012. Big data. Manag. Revolut. Harv. Bus Rev 90, 61-67.

McCrea, B., 2013. TMS: Trends driving adoption. Logist. Manag. 52, 32-34.

Mehmood, Lu, 2011. Computational Markovian analysis of large systemsnull. J. Manuf. Technol. Manag. 22, 804-817. doi:10.1108/17410381111149657

Mehmood, R., 2007. Towards Understanding Intercity Traffic Interdependencies, in: The 14th World Congress on Intelligent Transport Systems. ITS World Congress.

Mehmood, R., 2004a. Disk-based techniques for efficient solution of large Markov chains. University of Birmingham.

Mehmood, R., 2004b. Serial Disk-Based Analysis of Large Stochastic Models, in: Baier, C., Haverkort, B.R., Hermanns, H., Katoen, J.-P., Siegle, M. (Eds.), Validation of Stochastic Systems, Lecture Notes in Computer Science. Springer Berlin Heidelberg, pp. 230255.

Mehmood, R., Crowcroft, J., 2005. Parallel iterative solution method for large sparse linear equation systems. Comput. Lab. Univ. Camb.

Mehmood, R., Faisal, M.A., Altowaijri, S., 2015. Future Networked Healthcare Systems: A Review and Case Study. Book "Handbook Res. Redesigning Future Internet Archit. M Boucadair C Jacquenet Ed. 564-590.

Mehmood, R., Nekovee, M., 2007. Vehicular ad hoc and grid networks: discussion, design and evaluation. Proc. 14TH WORLD Congr. Intell. Transp. Syst. ITS HELD BEIJING Oct. 2007.

Miller, H.J., 2013. Beyond sharing: cultivating cooperative transportation systems through geographic information science. J. Transp. Geogr. 31, 296-308.

Moir, E., Moonen, T., Clark, G., 2014. What are Future Cities: Origins, Meanings and Uses. Government Office for Science/Future Cities Catapult.

Mourtzis, D., Doukas, M., 2013. Decentralized manufacturing systems review: challenges and outlook, in: Robust Manufacturing Control. Springer, pp. 355-369.

Prajogo, D., Olhager, J., 2012. Supply chain integration and performance: The effects of long-term relationships, information technology and sharing, and logistics integration. Int. J. Prod. Econ. 135, 514-522. 
Rai, A., Patnayakuni, R., Seth, N., 2006. Firm performance impacts of digitally enabled supply chain integration capabilities. MIS Q. 225-246.

Rigby, D., 2015. The Future of Shopping [WWW Document]. Harv. Bus. Rev. URL https://hbr.org/2011/12/the-future-of-shopping (accessed 9.1.15).

Ruiz-Torres, A.J., Nakatani, K., 1998. Application of real-time simulation to assign due dates on logistic-manufacturing networks, in: Proceedings of the 30th Conference on Winter Simulation. IEEE Computer Society Press, pp. 1205-1210.

Russom, P., 2011. The Three Vs of Big Data Analytics: TDWI.

Schlingensiepen, J., Mehmood, R., Nemtanu, F.C., Niculescu, M., 2014. Increasing Sustainability of Road Transport in European Cities and Metropolitan Areas by Facilitating Autonomic Road Transport Systems (ARTS), in: Wellnitz, J., Subic, A., Trufin, R. (Eds.), Sustainable Automotive Technologies 2013, Lecture Notes in Mobility. Springer International Publishing, pp. 201-210.

Schlingensiepen, J., Nemtanu, F., Mehmood, R., McCluskey, L., 2016. Autonomic Transport Management Systems - Enabler for Smart Cities, Personalized Medicine, Participation and Industry Grid/Industry 4.0, in: Sładkowski, A., Pamuła, W. (Eds.), Intelligent Transportation Systems - Problems and Perspectives, Studies in Systems, Decision and Control. Springer International Publishing, pp. 3-35.

Schroeck, M., Shockley, R., Smart, J., Romero-Morales, D., Tufano, P., 2012. Analytics: The real-world use of big data: How innovative enterprises extract value from uncertain data. IBM Inst. Bus. Value.

Scott, A., 2014. How Supply Chain Managers Dig Big Data. Mater. Handl. Logist. 69.

Setia, P., Patel, P.C., 2013. How information systems help create OM capabilities: Consequents and antecedents of operational absorptive capacity. J. Oper. Manag. 31, 409-431. doi:10.1016/j.jom.2013.07.013

Shah, N.D., Pathak, J., 2014. Why Health Care May Finally Be Ready for Big Data. Harv. Bus. Rev.

Slack, N., Lewis, M., 2011. Operations Strategy, 3rd ed. Pearson.

Sook-Ling, L., Ismail, M.A., Yee-Yen, Y., Brown, S., Brown, S., 2015. Information infrastructure capability and organisational competitive advantage: framework. Int. J. Oper. Prod. Manag. 35.

Stewart, W.J., 1991. Numerical Solution of Markov Chains. CRC Press.

Taniguchi, E., 2012. Concept and best practices practices of city logistics logistics.

Tushman, M.L., Nadler, D.A., 1978. Information Processing as an Integrating Concept in Organizational Design. Acad. Manage. Rev. 3, 613-624.

Whitier, K., 2014. IBM's New "Presence Zones" Help Retailers Transform In-Store Experience. Forbes, [WWW Document]. URL http://www.forbes.com/sites/kimberlywhitler/2014/01/09/ibms-new-presencezones-help-retailers-transform-in-store-experience/ (accessed 5.21.15).

Worthington, D., 1991. Hospital waiting list management models. J. Oper. Res. Soc. 833843.

Worthington, D.J., 1987. Queueing models for hospital waiting lists. J. Oper. Res. Soc. 413422.

Xu, F.Q., Ding, N., Lu, H.F., Liu, J., 2014. The data study and analyzing of city logistics system based on cloud platform. J. Chem. Pharm. Res. 6.

Yu, G., Hu, J., Zhang, C., Zhuang, L., Song, J., 2003. Short-term traffic flow forecasting based on Markov chain model, in: IEEE Intelligent Vehicles Symposium, 2003. Proceedings. 
Presented at the IEEE Intelligent Vehicles Symposium, 2003. Proceedings, pp. 208212. doi:10.1109/IVS.2003.1212910

Zelbst, P.J., Green, K.W., Sower, V.E., Reyes, P.M., 2012. Impact of RFID on manufacturing effectiveness and efficiency. Int. J. Oper. Prod. Manag. 32, 329-350.

Zhang, X., Pieter van Donk, D., van der Vaart, T., 2011. Does ICT influence supply chain management and performance? A review of survey-based research. Int. J. Oper. Prod. Manag. 31, 1215-1247. 